\title{
FUEGOS SAGRADOS. EL TALLER METALÚRGICO DEL SITIO 15 DE RINCÓN CHICO (CATAMARCA, ARGENTINA)
} SACRED FIRES. THE METALLRGICAL WORKSHOP OF STIE 15 AT RINCÓN

\author{
LUIS R. GONZÁlEZ *
}

\begin{abstract}
Numerosos estudios de laboratorio realizados sobre objetos de metal andinos aportaron valiosos datos sobre las características asumidas por la tecnología y el entramado simbólico en el cual se desarrollaron. Menos abundantes fueron los estudios de contextos de producción metalúrgica, en los cuales es posible recuperar evidencias directas sobre los modos de transformación de la materia aplicados y el papel social jugado por los productores. En estas páginas nos ocupamos del taller del Sitio 15 de Rincón Chico (valle de Yocavil, Noroeste Argentino), mencionando algunos aspectos de las técnicas desarrolladas y explorando su contenido simbólico. Se propone que la forma en que los antiguos metalurgistas planificaron las operaciones, la persistencia de algunos procedimientos y ciertas innovaciones introducidas se correlacionaron con la dinámica de complejización de la sociedad en la cual se inscribió el taller y los intereses particulares de los artesanos en el proceso.

Palabras clave: valle de Yocavil, taller metalúrgico, aspectos técnicos y simbólicos, complejidad social
\end{abstract}

Several lab analyses conducted on Andean metal objects contributed abundant and valuable data on features acquired by technology and the symbolic fabric in which it was embedded. Research has been less abundant on the contexts of metallurgical production that offered direct evidence about the methods used to transform materials and the social role of the producers. The article reviews the metallurgical workshop of the Rincón Chico 15 site (Yocavil Valley in Northwest Argentina), with some focus on the techniques developed there and their possible symbolic content. It proposes that the way in which the ancient metalworkers planned their operations, the persistency of some procedures, and certain innovations they introduced were related to the dynamics of an increasing social complexity of which the workshop itself was part, as well as to the particular interests of the artisans in that process.

Key words: Yocavil valley, metallurgical workshop, technical and symbolic aspects, social complexity

\section{INTRODUCCIÓN}

Los estudios de laboratorio realizados, a lo largo de los años, sobre objetos de metal andinos prehispánicos fueron numerosos y aportaron un enorme caudal de datos, en particular durante las últimas décadas, cuando los materiales metálicos comenzaron a considerarse como resultantes de una compleja organización productiva y simbólica que iba más allá de los minerales y las técnicas de elaboración aplicadas. También se expresaban en ellos modos particulares de concebir y tratar a la materia, así como tradiciones técnicas ancestrales, los valores atribuidos a los eventos tecnológicos y las prescripciones previstas para el desempeño de los objetos producidos (entre muchos, Lechtman 1999). Menos frecuentes fueron las investigaciones centradas en contextos de actividades metalúrgicas (por ejemplo, Shimada 1994; Graffam et al. 1994; Van Buren 2005; Uceda \& Rengifo 2006), en los cuales es posible recuperar evidencias sensibles para explorar cuestiones tales como la organización de la producción, las cualidades del estilo tecnológico aplicado y el papel desempeñado por los productos y por los productores en el marco de la formación social dentro de la cual las actividades tecnológicas estuvieron legitimadas.

En este sentido, comentaremos algunos datos surgidos de las investigaciones que, desde hace más de dos décadas, tienen lugar en el taller metalúrgico del Sitio 15 de Rincón Chico (Catamarca, Argentina), el

* Luis R. González, Museo Etnográfico Juan B. Ambrosetti (FFyL, UBA), Moreno 350 (1091), Buenos Aires, Argentina, email: zangolez@yahoo.com Recibido: enero de 2010. Aceptado: julio de 2010. 
cual operó, de acuerdo a 14 fechados radiocarbónicos, entre el siglo x y la conquista española. Los trabajos permitieron recuperar evidencias correspondientes a las distintas etapas de producción, en particular una gran variedad de materiales refractarios, algunos de ellos de cualidades poco conocidas en otras regiones andinas. A lo largo del prolongado lapso de ocupación, el taller fue aumentando su escala de producción y sufriendo remodelaciones en consonancia con la creciente complejización de la sociedad a la cual sirvió. Si bien durante la ocupación inkaica se introdujeron modificaciones organizativas, muchos de los procedimientos técnicos desarrollados localmente fueron conservados, al igual que los rangos de aleación de los bronces y los tipos de objetos producidos. A partir de los estudios realizados y del análisis de las operaciones que tenían lugar, se adelantan hipótesis relativas a los aspectos simbólicos de ciertas decisiones técnicas.

\section{LA METALURGIA DEL ANTIGUO NOROESTE ARGENTINO}

La metalurgia prehispánica del Noroeste Argentino (NOA) representa un ilustrativo caso que pone de relieve la intrincada articulación de la tecnología con diferentes dimensiones de la vida social y de la cultura. Los datos acumulados a lo largo de más de una centuria de investigaciones sugieren que la metalurgia de la región conformó una tradición con características propias, no sólo en las cualidades formales de los bienes elaborados, sino también en los procedimientos tecnológicos puestos en juego para ello. Esta tradición estuvo sustentada en la elaboración del bronce estañífero y habría alcanzado su más alta expresión entre los siglos x y xv.

Tal como se verifica en otros lugares del mundo andino, las fuerzas que impulsaron las innovaciones en la producción de metales en el NOA respondieron a los procesos históricos que condujeron al fortalecimiento de organizaciones sociales cada vez más complejas y con mayor diferenciación en el posicionamiento de sus miembros a la hora de acceder al poder y a los recursos. Las cualidades del metal fueron aprovechadas para elaborar pequeñas herramientas para la vida diaria pero, en lo fundamental, para dar a luz símbolos materiales de distinción social y de conexión con los dioses tutelares. A través de estos bienes, del modo de realizarlos y de las prescripciones para su uso, se manifestaron los fundamentos de la cosmovisión andina y de los principios que regulaban el devenir del mundo, además de materializarse la ideología que gobernaba la vida cotidiana (González, L. 2002a).
La experimentación sistemática del trabajo del cobre y sus aleaciones parece haber comenzado en los valles centrales y orientales de la provincia de Catamarca, hacia, por lo menos, mediados del primer milenio antes de la Era (González, L. 2008: 59-60). Pero fue en el contexto de las sociedades La Aguada ( $c a$. 450-900 DC) cuando, impulsada por el aumento de las diferenciaciones sociales y de las prácticas religiosas, la producción de objetos de metal ganó en sofisticación, con innovaciones técnicas como el método de colada por "cera perdida" y una mayor popularidad del bronce al estaño. Acerca de este fenómeno -pero con validez para los siglos que vendrían-Alberto Rex González se encargó de destacar que:

La cultura de La Aguada del N. O. argentino fue una de las primeras en utilizar bronce en Sudamérica. Pero poco significado tuvo esta aleación en la aplicación práctico-utilitaria de esta cultura. La casi totalidad de los objetos de bronce o su gran mayoría eran objetos puramente suntuarios o relacionados con el ritual y el ceremonialismo. Estaban destinados a satisfacer la demanda de una elite. No de subvenir a las necesidades prácticas de la mayoría (González, A. 1998: 367).

La tradición metalúrgica del Noroeste alcanzó su más alta expresión durante las épocas tardías. Las transformaciones sociales iniciadas en el siglo x, con el crecimiento de extensos poblados aglomerados, aumento demográfico, mejoras en los sistemas de producción de alimentos, la consolidación de liderazgos, jerarquías internas y prácticas ceremoniales, estimularon la elaboración de bienes de prestigio (Tarragó \& González 1996). El aumento de la escala de producción de metales se tradujo tanto en la cantidad y la variedad de las piezas elaboradas como en el volumen de material invertido en cada una de ellas. El bronce de cobre y estaño se utilizó para la manufactura de todo tipo de objetos, cuyos modelos se mantuvieron en producción bajo los posteriores tiempos de dominación inkaica.

Se observa un crecimiento en el número de herramientas, por lo común de pequeño tamaño, lo cual puede vincularse con el desarrollo de otras artesanías (cerámica, tejido, madera), lo que habría conducido a que los operarios contaran con equipos de trabajo especializados que incluían instrumentos metálicos. Pero los avances técnicos de la metalurgia tardía se muestran en toda su magnitud en los objetos suntuarios, algunos de los cuales, además de alcanzar grandes dimensiones y varios kilogramos de peso, asumieron características únicas en el concierto andino. Entre ellos cabe mencionar a las manoplas o tensores, las placas y los discos, las campanas de sección oval y los cetros o hachas, materiales todos ellos que sumaron a su compleja elaboración los símbolos iconográficos reconocidos de la época (González, L. 2008; véase fig. 1). 

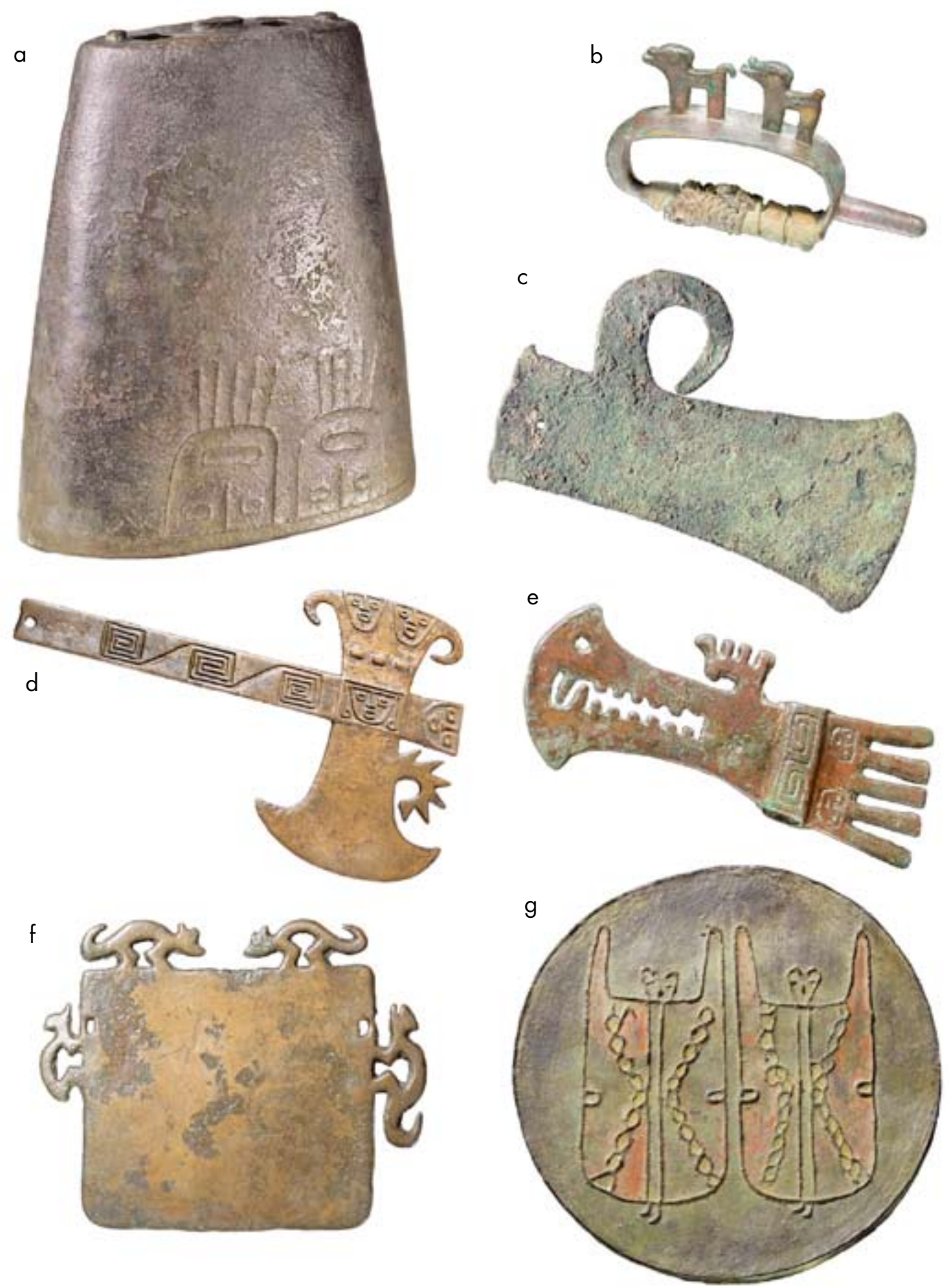

Figura 1. Bronces del Noroeste de épocas tardías. A) Campana oval (alto $32,5 \mathrm{~cm}$ ); B) manopla (largo $13,2 \mathrm{~cm}$ ); C) hoja de hacha plana (largo $21 \mathrm{~cm}$ ); D) hacha con mango (alto $25,3 \mathrm{~cm}$ ); E) cabezal de hacha con tubo para enmangue (largo 27,3 cm); F) placa rectangular (alto 15,5 cm); G) disco (diámetro 19,5 cm). Fotos Fundación CEPPA (A, B, D, E, F y G, Colección Ministerio de Relaciones Exteriores; C, Museo Wagner).

Figure 1. Bronze pieces from the Northwest, late period. A) Oval bell (height: $32.5 \mathrm{~cm}$ ); B) handle (length: $13.2 \mathrm{~cm}$ ); C) flat axe head (length: $21 \mathrm{~cm}$ ); D) axe with handle (height: $25.3 \mathrm{~cm}$ ); E) axe head with tube for inserting handle (length: $27.3 \mathrm{~cm}$ ); F) rectangular plaque (height: $15.5 \mathrm{~cm}$ ); G) disc (diameter: $19.5 \mathrm{~cm}$ ). Photos: Fundación CEPPA (A, B, D, E, F and G, Ministerio de Relaciones Exteriores Collection; $C$, Museo Wagner). 
La manufactura de objetos como los mencionados demandó la ejecución de una compleja serie de tareas, que se iniciaban con la selección de las materias primas minerales en sus depósitos. El proceso de transformación exigía, en ciertas etapas, contar con instalaciones, herramientas e insumos adicionales específicos (González, L. 2004). Pero lo más importante era la intervención de operarios experimentados en el comportamiento de los materiales bajo condiciones extremas y altamente calificados para llevar a cabo los procedimientos técnicos. La idoneidad y el entrenamiento de los metalurgistas norteños fueron aprovechados por los administradores inkaicos cuando, durante la primera mitad del siglo xv, la región fue integrada al Tawantinsuyu. Bajo esta administración y como en otras zonas andinas, parecen haberse introducido algunas modificaciones organizativas en los sistemas de trabajo, tendientes al aumento de la salida de metales. De igual modo, un puñado de nuevos modelos de piezas fue incorporado a los objetivos de producción. Pero, como se adelantara, los materiales con reconocimiento local continuaron siendo elaborados.

Entre los contextos de trabajo metalúrgico que operaron durante las épocas tardías, algunos de ellos reocupados o fundados por el estado cusqueño (véase González et al. 2008), el más intensamente investigado y que proporcionó la mayor cantidad de información sobre estas actividades en la región es el denominado Sitio 15 de Rincón Chico, en el valle de Yocavil meridional.

\section{EL SITIO 15 DE RINCÓN CHICO}

Rincón Chico, a $5 \mathrm{~km}$ al suroeste de la ciudad de Santa María, provincia de Catamarca, constituye un ilustrativo caso de los extensos poblados que se desarrollaron a partir del siglo x en la región valliserrana del NOA. Treinta y ocho fechados radiocarbónicos muestran una ocupación de al menos 700 años, hasta avanzada la dominación europea del territorio (Tarragó 2007: 18). La máxima expansión de Rincón Chico se habría alcanzado a principios del siglo xv, cuando habría constituido la cabecera de un sistema de complementariedad funcional que articulaba otros poblados del sur del valle. El proceso de complejización social que acompañó el desarrollo de las bases productivas se observa, entre otros aspectos, en las diferencias arquitectónicas intrasitio, la sectorización de los espacios constructivos y el crecimiento de las áreas ceremoniales. A lo largo de este proceso, las elites político-religiosas habrían centralizado una extensa red de interacción macrorregional en la cual determinados bienes, en particular las artesanías de prestigio identificadas con el estilo "santamariano", tuvieron la oportunidad de llegar a territorios tan distantes como las provincias de Cuyo y el norte de Chile (Tarragó \& González 2004).

El asentamiento cubre un área de unas 500 ha y se compone de 39 sitios, siendo el principal el denominado Sitio 1, un poblado aglomerado con más de 360 estructuras con paredes de piedras distribuidas sobre la cima y la ladera de un espolón que se desprende de la sierra del Cajón. Hacia el oriente, por la llanura aluvial que desciende hacia el río Santa María, se ubican los restantes sitios, que asumen distintas características. La mayoría se trata de conjuntos constructivos compuestos por una gran estructura rectangular a la que se adosan recintos más pequeños, rectangulares y circulares (Tarragó 1998).

El Sitio 15 (Lat. 26 42' 22.6” S, Long. 66 04' 21.6" W) se emplaza a más de 1000 metros de la serranía donde se encuentra el Sitio 1 (fig. 2). Las estructuras fueron levantadas al borde de terrenos que, en épocas prehispánicas, albergaban un potente bosque de maderas duras (González, L. 2001 Ms.). El sitio se compone de un recinto rectangular de $34 \mathrm{~m}$ de largo por $24 \mathrm{~m}$ de ancho, denominado E1, que se comunica mediante un pasillo con un espacio poligonal designado E2 ubicado hacia el este. A partir de esta modalidad de comunicación, el conjunto constructivo impresiona como "dando la espalda" al resto de los sitios de la planicie y al cerro donde se ubica el Sitio 1. La estructura E2, a su vez, también estaba abierta hacia el este, continuando un amplio espacio que desemboca en una estructura monticular alargada, en sentido norte-sur, denominada Montículo Oriental (MO). Unos $35 \mathrm{~m}$ al sur de E1 se presenta otra estructura levemente elevada, el Montículo Meridional (MM), que cubre un espacio de $70 \mathrm{~m}^{2}$. Hacia el norte de las construcciones se encuentra un área $(\mathrm{ZN})$ que no presenta evidencias de muros en superficie pero que sí se los descubre enterrados. El área arqueológica del Sitio 15 está calculada en $5.500 \mathrm{~m}^{2}$ (Tarragó 2007), habiéndose intervenido hasta el momento $531 \mathrm{~m}^{2} \mathrm{con}$ excavaciones (fig. 3).

Los primeros trabajos, con levantamientos de planos y sondeos exploratorios, se realizaron en 1987. En los años que siguieron se efectuaron excavaciones en área en E1, E2, MM y diversos sectores de MO, abriéndose también trincheras de distinta extensión al norte de las estructuras. Catorce dataciones radiocarbónicas enmarcan la ocupación del sitio entre los siglos x y XVII (Tarragó 2007; Marchegiani, com. pers. 2009). La estructura fundante habría sido E1, sucediéndose luego importantes remodelaciones y ampliaciones del espacio hasta culminar con la incorporación del área norte (donde a mediados del siglo pasado se investigaron cámaras mortuorias 


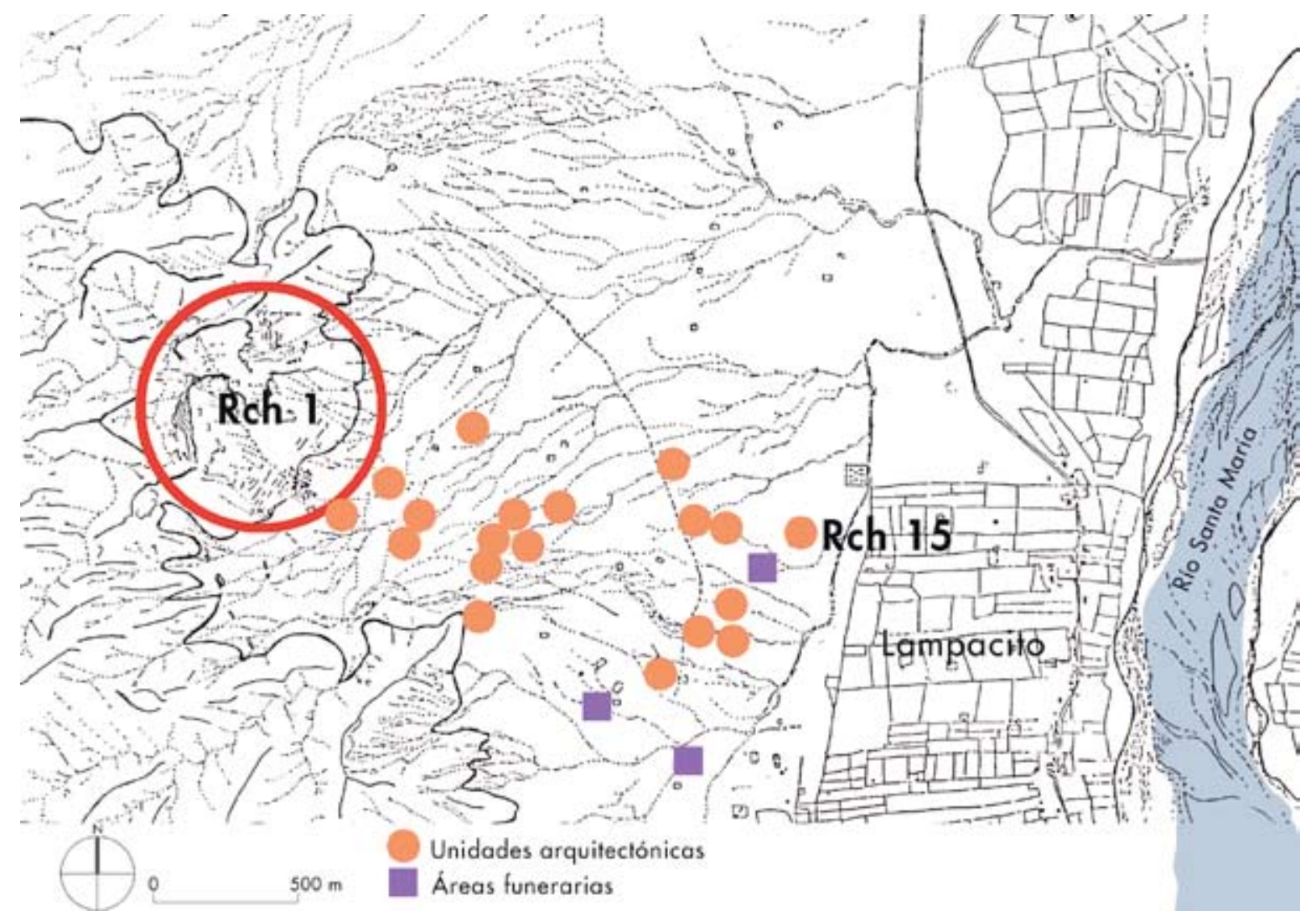

Figura 2. Ubicación del Sitio 15 dentro la localidad de Rincón Chico.

Figure 2. Location of Site 15 in the locality of Rincón Chico.

con materiales europeos que ubican los contextos en los siglos XVI a XVII; Tarragó 2007: 21). A menos de 100 metros hacia el suroeste se ubica el Sitio 11, un lugar funerario, en la actualidad muy perturbado, que cubre una superficie mínima de $400 \mathrm{~m}^{2}$ y que habría estado vinculado con el Sitio 15 (Tarragó 1998).

En las muestras cerámicas obtenidas tanto en superficie como en las excavaciones en el Sitio 15, la proporción dominante corresponde a fragmentos del estilo Santa María en diferentes variantes. En muy bajos porcentajes aparecen especímenes de otros tipos locales, y ningún fragmento de vasija asimilable a los estilos inkaicos reconocidos ha sido catalogado. Durante las excavaciones fueron identificados dos locus de producción alfarera y el estudio de los abundantes restos óseos de fauna sugiere que el consumo principal era de camélidos, complementado con la caza de animales silvestres. De igual modo, fueron identificados marlos de maíz y semillas de maní, cucurbitáceas y algarroba. Entre el material lítico se cuentan lascas, núcleos y puntas de proyectil de obsidiana, roca cuya fuente de procedencia se encontraría fuera del valle de Yocavil (Tarragó 2007: 22-23).

\section{ARQUEOMETALURGIA EN RINCÓN CHICO 15}

La faceta más llamativa del registro arqueológico del Sitio 15 es la cantidad y calidad de evidencias relacionadas con actividades metalúrgicas, las cuales se documentaron en distintos sectores del lugar y se relacionan, directa o indirectamente, con todas las etapas de producción (González, L. 2001, 2002b; González \& Gluzman 2007a). Cubetas de combustión caracterizadas por la presencia de carbón, cenizas, escorias de combustión (VFA [Vitrified Fuel Ash]; Tylecote 1987) y sedimentos termoalterados, asociadas en todos los casos a fragmentos de minerales y de refractarios de distintos tipos, fueron identificadas en la esquina sureste de E1, en el área extramuros sur y sobre todo en las porciones central y norte de $\mathrm{MO}$ (fig. 4). Cabe señalar que a lo largo de unos 50 metros en este último rasgo afloran en superficie numerosos manchones de sedimentos carbonosos, así como restos de refractarios, lo que señala la presencia de estructuras de combustión metalúrgicas sepultadas. Por su parte, en MM fueron descubiertas cinco estructuras circulares, de piedra, con 


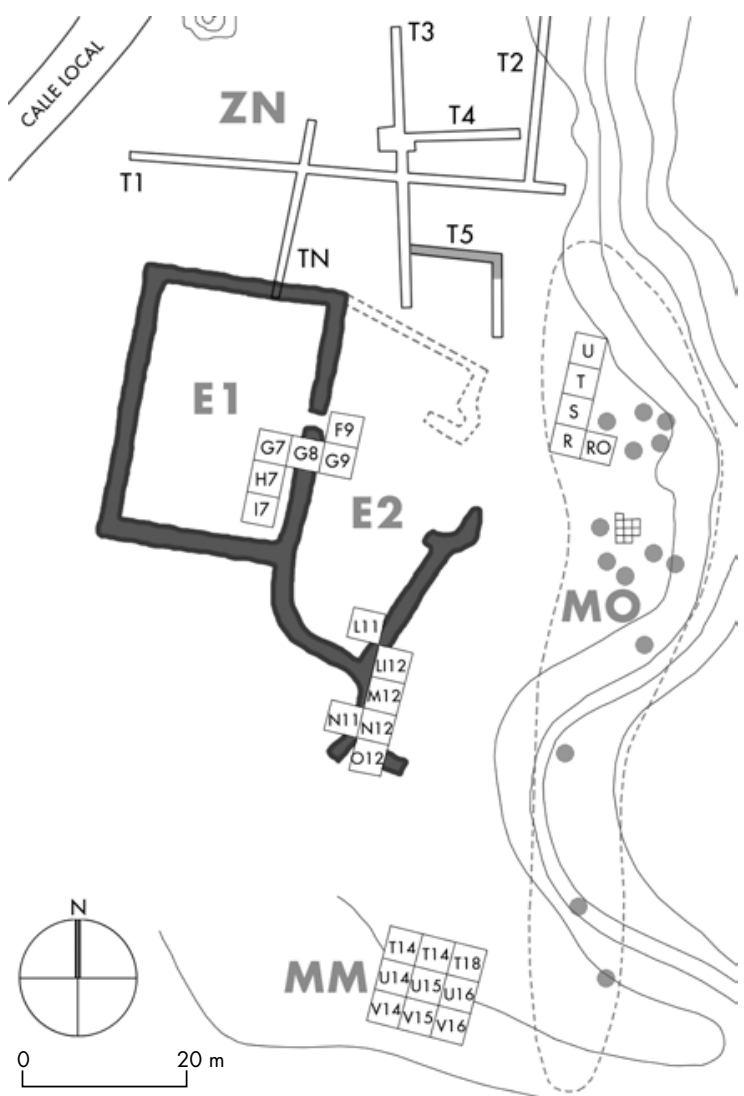

Figura 3. Planta esquemática del Sitio 15. Los círculos oscuros en MO indican áreas de trabajo metalúrgico sepultadas.

Figure 3. Layout of Site 15. The dark circles at MO indicate buried areas of metallurgical work.

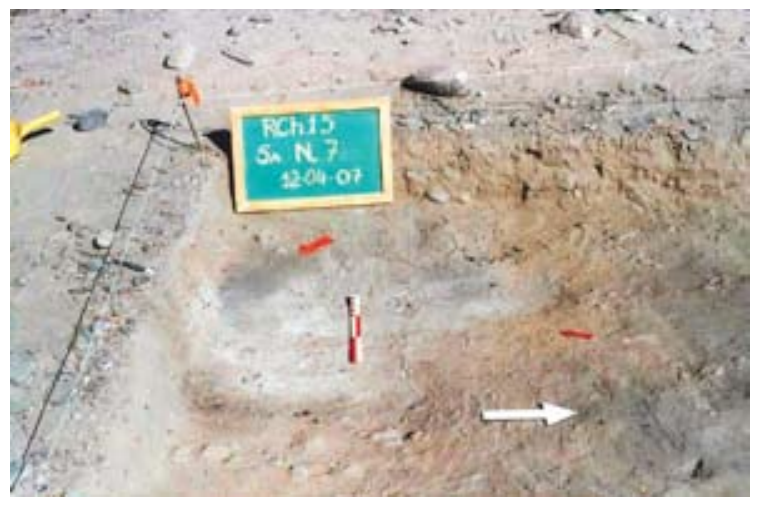

Figura 4. RCh 15. Estructura de combustión de actividades metalúrgicas, en el sector norte del MO.

Figure 4. RCh 15. Structure of combustion related to smelting activities in the northern sector of $M O$.

un diámetro en torno a los $50 \mathrm{~cm}$ y apoyadas sobre sedimentos con signos de extrema termoalteración. La gran cantidad de rodados y trozos poliédricos de rocas, de aporte antrópico y con signos de haber estado sometidos a altas temperaturas, llevaron a postular que las estructuras constituyeron las bases de pequeños hornos de fundición del tipo buayra instalados durante la ocupación inkaica (González 2002b).

Los fragmentos de minerales metálicos recuperados corresponden, mayoritariamente, a compuestos oxidados de cobre, algunos de los cuales se alteraron a cloruros por fenómenos posdepositacionales. Este tipo de menas se ajusta a la información geológica regional, siendo compatibles con mineralizaciones conocidas en un rango entre 30 y $80 \mathrm{~km}$ al sur del Sitio 15. Los fragmentos son muy pequeños y de alta ley, lo cual sugiere que fue explotado, tal vez selectivamente, un filón rico y que los minerales extraídos se sometieron a operaciones de molienda y separación del estéril en bocamina (fig. 5). De acuerdo a la composición de las incrustaciones metálicas recuperadas de las paredes de refractarios y de las gotas de fundición (prills) analizadas (véanse Tablas 1 y 2), sabemos que en el taller se manufacturaban bronces al estaño, pero durante los trabajos no fue registrado ningún resto del mineral correspondiente, lo cual puede atribuirse a un defecto de muestreo, teniendo en cuenta que este recurso crítico probablemente tenga menor representación arqueológica. Al respecto, las fuentes de estaño más cercanas conocidas se localizan en un rango de 140 a $170 \mathrm{~km}$ al suroeste (González, L. 2002b).

Es de interés señalar que, no obstante las evidencias de prolongadas e intensas actividades en el lugar, los hallazgos de objetos de metal (como piezas terminadas, rotas, falladas o preformas) fueron nulos, lo cual sugiere que el consumo de los productos elaborados era exterior a la unidad de producción. Los únicos metales recuperados fueron gotas o prills, probablemente extraviados durante el vaciado de los crisoles (fig. 6). Estos materiales son frecuentemente referidos como productos de la fundición en estos contenedores (por ejemplo, Tylecote 1974; Rovira 2004) y también fueron obtenidos en nuestras propias experimentaciones diseñadas para aclarar el punto (González et al. 2007). Las gotas arqueológicas son de pequeño diámetro y aparecen fuertemente alteradas, con una capa exterior de paratacamita (fig. 6), un producto clásico de la corrosión de bronces y cobres (entre muchos, Scott 2000; De Oliveira et al. 2009). Determinaciones químicas fueron efectuadas sobre 26 gotas, constatándose que en tres casos se trataba de bronces estañíferos, lo cual evidencia la elaboración de la aleación en los crisoles (Tabla 1).

Otras 27 muestras metálicas analizadas fueron extraídas de las superficies de diferentes refractarios. Como puede observarse en la Tabla 2, el cobre es el elemento 


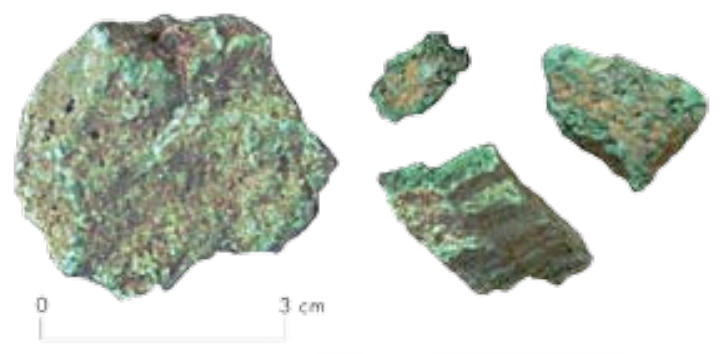

Figura 5. RCh 15. Ejemplos de fragmentos de minerales de cobre. Nótese el grado de conminución.

Figure 5. RCh 15. Fragments of copper ore. Note the degree of comminution.

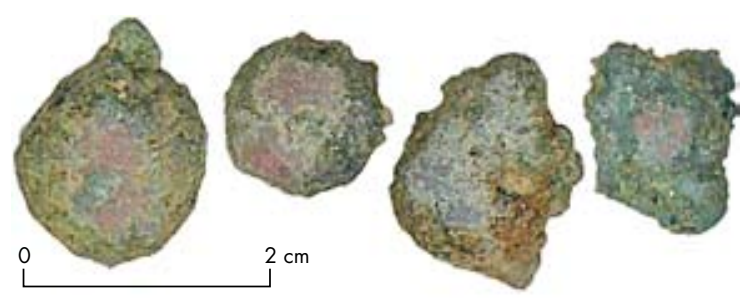

Figura 6. RCh 15. Ejemplos de gotas de fundición.

Figure 6. RCh 15. Hardened drops from smelting process.

siempre presente, en combinaciones que tienden a variar de acuerdo al tipo de refractario. En las muestras correspondientes a crisoles las composiciones detectadas impresionan como anómalas, atribuyéndose esta característica a la probable reutilización de las piezas con la consiguiente contaminación de los productos. Para destacar son las muestras 532, con muy alta representación de estaño, y las 519a y 520b, con oro como elemento mayoritario. Varias otras muestras contienen cinc, algunas en cantidades significativas. No obstante, se considera que este elemento es resultado de una contaminación de la mena de origen y que iría perdiendo representación a medida que avanzara el proceso de elaboración de los metales (González et al. 2007).

\section{MOLDES, CRISOLES Y CUCHARAS}

Los fragmentos de refractarios representan la evidencia arqueometalúrgica más conspicua del taller del Sitio 15. Fueron clasificados, de acuerdo al tipo de piezas a las cuales correspondieron, en tres categorías funcionales: moldes, crisoles y cucharas o intermediarios. Los estudios de laboratorio, realizados sobre distintas muestras y utilizando diferentes técnicas, confirmaron que las piezas estuvieron sometidas a temperaturas superiores
Tabla 1. RCh 15. Composición de gotas de fundición (EDS, \% en peso, sólo Cu y Sn. Resto: $\mathrm{Fe}, \mathrm{Cl}, \mathrm{Si}, \mathrm{Ca}, \mathrm{K}$ ). Table 1. RCb 15. Composition of drops from the smelting process (EDS, \% by weight, Cu and Sn only. Other: $\mathrm{Fe}, \mathrm{Cl}, \mathrm{Si}, \mathrm{Ca}, \mathrm{K}$ ).

\begin{tabular}{|c|c|c|}
\hline $\mathbf{N}^{\circ}$ procedencia & Cu (\%) & Sn (\%) \\
\hline 97 & 85,87 & 14,13 \\
\hline 511 & 97,18 & - \\
\hline 513 & 66,00 & 19,60 \\
\hline 753 & 94,15 & - \\
\hline 758 & 90,83 & - \\
\hline $796 a$ & 93,11 & - \\
\hline $796 b$ & 91,17 & - \\
\hline 797 & 87,91 & - \\
\hline 801 & 93,48 & - \\
\hline 884 & 81,84 & - \\
\hline $950 a$ & 92,85 & - \\
\hline $950 b$ & 89,45 & - \\
\hline $950 c$ & 93,37 & - \\
\hline $950 d$ & 89,54 & 7,69 \\
\hline $950 e$ & 92,17 & - \\
\hline $950 f$ & 95,55 & - \\
\hline 953 & 91,28 & - \\
\hline 954 & 88,64 & - \\
\hline 1000 & 91,75 & - \\
\hline 1002 & 94,73 & - \\
\hline 1003 & 93,91 & - \\
\hline 1005 & 95,28 & - \\
\hline 1008 & 96,12 & - \\
\hline 1011 & 94,57 & - \\
\hline 1012 & 93,08 & - \\
\hline 1013 & 89,58 & - \\
\hline & & \\
\hline
\end{tabular}

a $800{ }^{\circ} \mathrm{C}$, superando, en el caso de los crisoles, los $1100{ }^{\circ} \mathrm{C}$ (Pradell et al. 2009). Las cualidades petrográficas de las pastas sugieren que el comportamiento de los materiales bajo condiciones de altas temperaturas fue optimizado con el agregado de altas cargas de antiplásticos a la matriz arcillosa (González, L. 2001). Las excepciones, en este punto, están constituidas por los moldes de cera perdida, una técnica de colada preferida para la elaboración de piezas con formas o decoración complejas (González, L. 2004: 131-132) y de los cuales se registraron casi una treintena de fragmentos en distintos lugares (fig. 7). 
Tabla 2. RCh 15. Composición de adherencias metálicas en refractarios (EDS, \% en peso, sólo elementos metálicos. Resto: Cl, Si, Ca, K).

Table 2. RCh 15. Composition of refractory metallic adherences (EDS, \% by weight, only metallic elements. Other: $\mathrm{Cl}$, Si, Ca, K).

\begin{tabular}{|c|c|c|c|c|c|c|c|}
\hline Material & $\mathrm{N}^{\circ}$ procedencia & $\mathrm{Cu}(\%)$ & Sn $(\%)$ & Zn (\%) & $\mathrm{Fe}(\%)$ & $\mathrm{Au}(\%)$ & $\mathrm{Ag}(\%)$ \\
\hline Molde & 497 & 89,05 & 6,59 & 1,22 & 2,17 & - & - \\
\hline Molde & $511 \mathrm{a}$ & 91,54 & - & - & 8,45 & - & - \\
\hline Molde & $511 b$ & 95,80 & - & - & 3,90 & - & - \\
\hline Molde & 515 & 94,30 & - & - & 5,69 & - & - \\
\hline Crisol & 518 & 62,48 & - & - & 2,05 & 34,65 & - \\
\hline Crisol & $519 \mathrm{a}$ & 11,42 & - & - & 18,95 & 69,27 & - \\
\hline Molde & $519 b$ & 82,05 & - & - & 17,95 & - & - \\
\hline Molde & $520 \mathrm{a}$ & 97,18 & - & - & 2,82 & - & - \\
\hline Crisol & $520 \mathrm{~b}$ & 28,15 & - & - & 1,81 & 69,70 & - \\
\hline Molde & 521 & 91,43 & - & - & 8,57 & - & - \\
\hline Crisol & $527 \mathrm{a}$ & 59,40 & - & 16,31 & 24,29 & - & - \\
\hline Crisol & $527 \mathrm{~b}$ & 66,62 & - & 10,24 & 23,13 & - & - \\
\hline Crisol & $527 \mathrm{c}$ & 74,99 & - & 1,42 & 23,58 & - & - \\
\hline Crisol & 532 & 22,15 & 52,70 & - & 12,06 & 6,06 & 6,21 \\
\hline Crisol & $533 a$ & 95,11 & - & 4,88 & - & - & - \\
\hline Crisol & $533 b$ & 64,75 & - & 14,84 & 1,48 & 18,93 & - \\
\hline Molde & $534 a$ & 92,51 & - & - & 7,48 & - & - \\
\hline Crisol & $534 b$ & 64,36 & - & - & 3,18 & 31,84 & 0,61 \\
\hline Molde & 535 & 84,32 & 8,16 & - & 3,02 & 4,21 & - \\
\hline Crisol & 537 & 72,71 & - & 14,13 & 13,15 & - & - \\
\hline Molde & 538 & 98,81 & 1,18 & - & - & - & - \\
\hline Molde & 543 & 93,53 & - & - & 6,46 & - & - \\
\hline Molde & 546 & 93,70 & 1,34 & - & 1,34 & - & - \\
\hline Molde & 797 & 79,24 & - & - & 2,94 & - & 2,90 \\
\hline Crisol & 886 & 79,35 & 11,05 & 2,78 & 5,09 & - & - \\
\hline Crisol & 893 & 85,72 & - & 1,42 & 4,14 & - & 6,39 \\
\hline Crisol & 894 & 95,08 & - & 1,75 & 1,82 & - & 0,40 \\
\hline
\end{tabular}



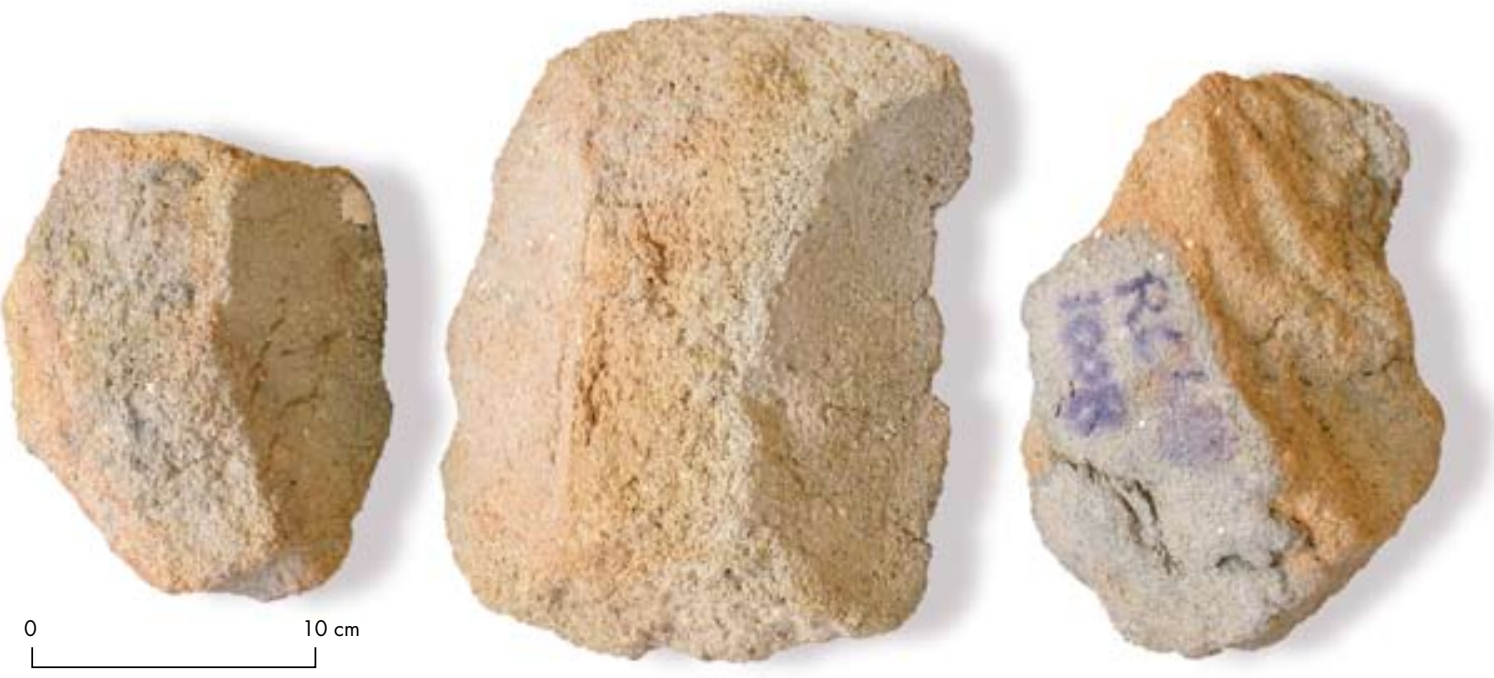

Figura 7. RCh15. Fragmentos de moldes de cera perdida. Figure 7. RCh15. Fragments from lost wax casting.

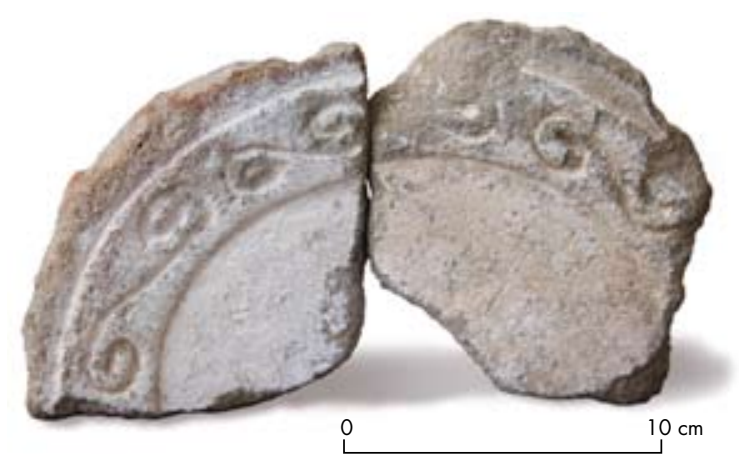

Figura 8. RCh 15. Fragmentos de molde de disco. Figure 8. RCh 15. Fragment of disc mold.

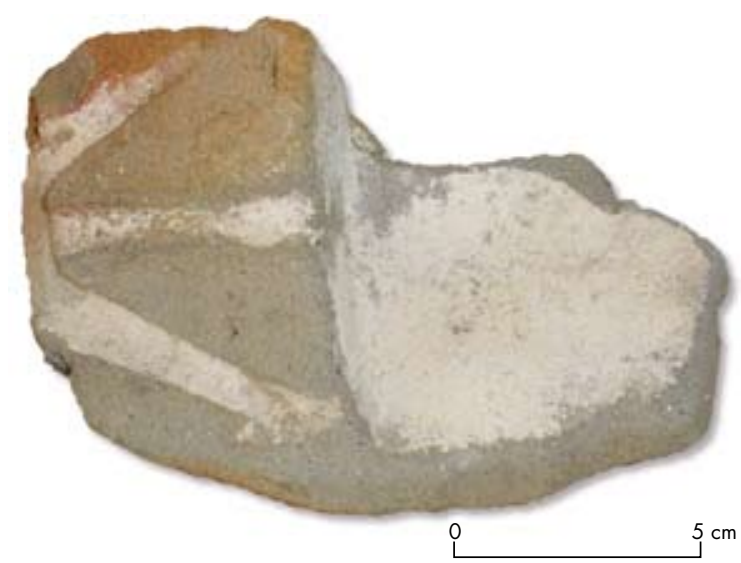

Figura 9. RCh15. Fragmento de molde de campana oval. Figure 9. RCh15. Fragment of oval bell mold.
Se identificaron moldes utilizados para colar cinceles, hachas, los clásicos discos de la época y, por primera vez en la arqueología del NOA, campanas ovales (figs. 8 y 9). En MM fueron recuperados fragmentos de dos pequeños moldes de lingotes y en $\mathrm{ZN}$ los fragmentos de un molde de lingote de $5 \mathrm{~cm}$ de alto por $8 \mathrm{~cm}$ de ancho. Cabe señalar que en varios casos los objetos colados no llegan a ser identificados, en razón del grado de fragmentación de los refractarios o por no reconocerse las formas de acuerdo al repertorio de materiales metálicos de la región (fig. 10).

Los crisoles, por su parte, fueron recipientes en forma de cuenco, con un diámetro en la boca entre 10 y $15 \mathrm{~cm}$ y una altura algo menor. Las paredes son

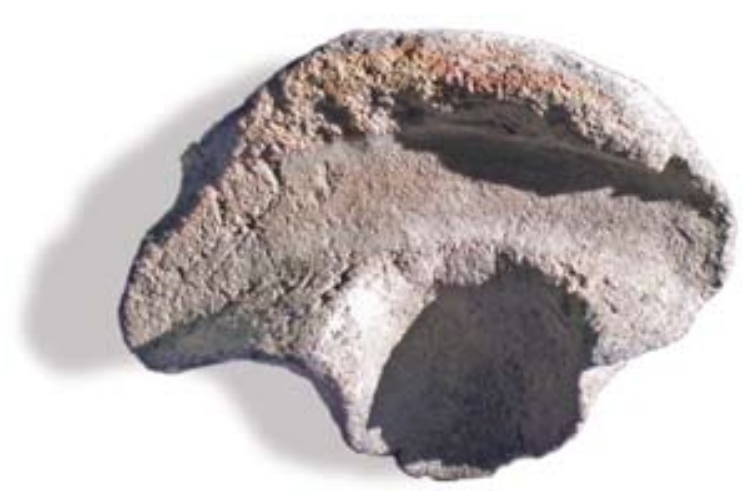

Figura 10. RCh15. Ejemplo de fragmento de molde de un objeto no identificado (dimensión máxima, $6,5 \mathrm{~cm}$ ).

Figure 10. RCh15. Fragment of a mold of an unidentified object (maximum size $6.5 \mathrm{~cm}$ ). 
gruesas y terminadas con un alisado expeditivo. En algunos casos, cerca del borde se advierte una muesca perimetral o una leve curvatura, probablemente destinadas a fijar un dispositivo de agarre para movilizar las piezas (véase más adelante). No obstante, al parecer también operaban crisoles de mayor tamaño, como es el caso de una pieza (Procedencia $\mathrm{N}^{\circ} 786$ ) fracturada in situ en una estructura de combustión (con un fechado de $650 \pm 60$ años $C^{14} \mathrm{AP}, \mathrm{LP}-1461$ ), cuya boca habría asumido un diámetro de entre 25 y $28 \mathrm{~cm}$. Las pastas de los crisoles son de color gris negruzco, en parte sinterizadas por las altas temperaturas. En las superficies internas suelen observarse vitrificaciones que alcanzan espesores de hasta $3 \mathrm{~mm}$, promovidas por las reacciones del material cerámico con el metal, los fundentes y las cenizas del combustible a elevados rangos térmicos (González, L. 2001).

Un caso particular de refractarios son los denominados "intermediarios" o "cucharas", piezas formalmente similares a los crisoles pero que se caracterizan por poseer una perforación circular en el fondo, la cual habría sido utilizada para el drenaje del metal fundido sobre los moldes, controlando el vertido mediante un tapón. Existen contadas referencias sobre refractarios similares recuperados en los Andes Meridionales (Debenedetti 1917; Niemeyer 1981; Raffino et al. 1996; González, L. 1997). Acerca del modo de operación, la propuesta más aceptada es la de Niemeyer (1981: 97), quien estimó que las cucharas estaban destinadas a recoger el metal fundido para distribuirlo sobre los moldes, retirando un vástago que ocluía el agujero inferior. Al momento, para el Sitio 15 se cuenta con dos identificaciones seguras, que corresponden a fragmentos en los que se distinguía el agujero del fondo y que se recuperaron asociados a sus tapones, también de material refractario (figs. 11 y 12). Otros tres tapones, los que se manejarían fijados a mangos de madera, se registraron asociados a fragmentos de recipientes similares pero que no pudieron identificarse fehacientemente como cucharas al no poderse constatar la presencia del agujero de drenaje.

Las cavidades de los moldes, crisoles y cucharas presentan un baño blanquecino (véanse figs. 8, 9, y 11), característica que fuera señalada para muchos refractarios del Noroeste (González, A. 1992: 134, 1998: 102; Raffino et al. 1996: 67-68; Angiorama 2005: 191). En el caso de los materiales del Sitio 15, los resultados de 29 análisis por EDS y DRX indicaron que el recubrimiento se trata principalmente de hidroxiapatita $\left(\mathrm{Ca}_{10}\left(\mathrm{PO}_{4}\right)_{6}(\mathrm{OH})\right.$, logrado con una solución de cenizas de huesos (Gráfico 1). Desde lo funcional, el recubrimiento pudo haber actuado como suavizante

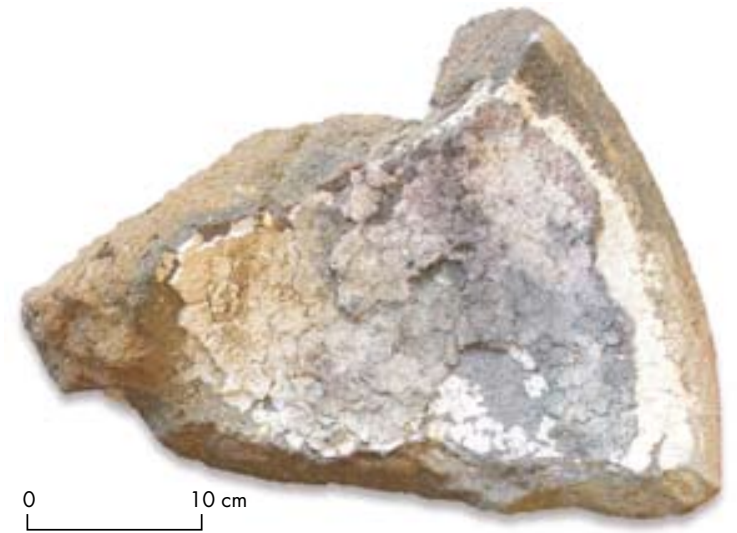

Figura 11. RCh15. Fragmento de cuchara, con parte del agujero drenaje (abajo, a la izquierda).

Figure 11. RCh15. Fragment of a ladle with part of the drainage bole (lower left).

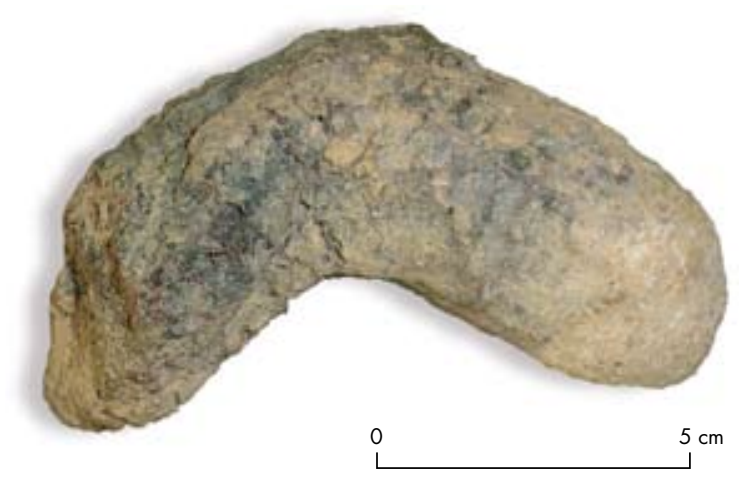

Figura 12. RCh15. Fragmento de tapón de cuchara.

Figura 12. RCh15. Fragment of a ladle stopper.

de las superficies de los refractarios, como protector de la acción erosiva del metal fundido y, tal vez, le habría otorgado una mayor resistencia estructural al material cerámico (González, L. 1992: 60, 1997; Pradell et al. 2009; Gluzman et al. 2009)

Es de interés señalar otro aspecto técnico de algunos de los crisoles registrados en el taller y que probablemente se vinculara con la movilización de las piezas cargadas con metal fundido desde las estructuras de fundición hasta los moldes. Esta no era, para los antiguos operarios, una tarea menor, si se tiene en cuenta que los recipientes se encontraban a más de $1000{ }^{\circ} \mathrm{C}$ y podían llegar a pesar, llenos de metal, un par de kilos. Para empeorar la situación, el tiempo del que se disponía para colar el material fundido antes que comenzara a oxidarse y perder fluidez era escaso (Tylecote 1987: 188). El método de sujeción utilizado por los antiguos metalurgistas que es citado con mayor frecuencia en la literatura es la utilización de ramas verdes y flexibles 


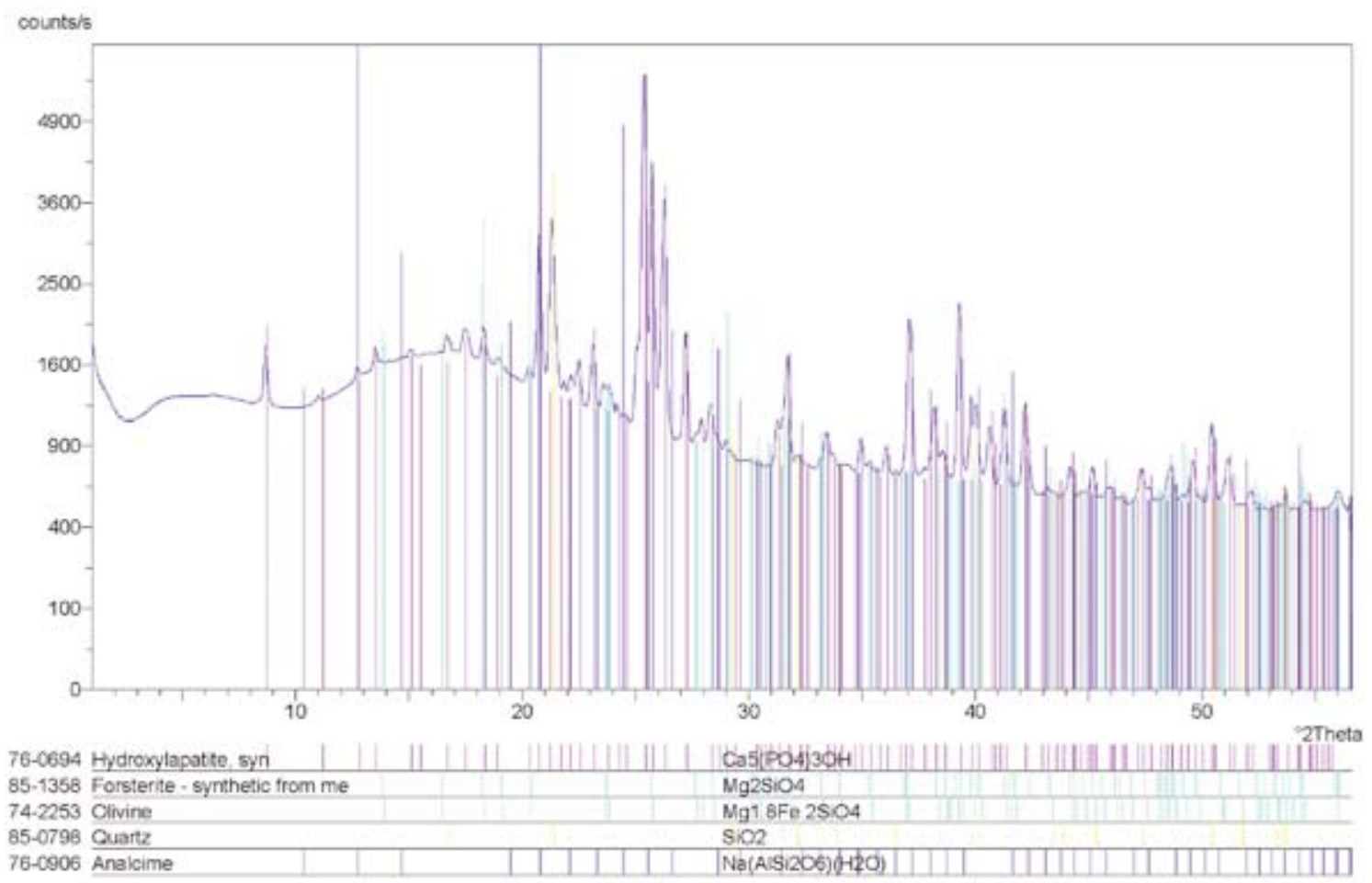

Gráfico 1. Espectro DRX de una muestra de recubrimiento blanquecino, identificado como hidroxiapatita (tomado de Pradell et al. 2009). Graph 1. DRX spectrum of a sample of white coating identified as Hydroxylapatite (from Pradell et al. 2009).

que se disponían a los lados del recipiente, ajustándose a alguna muesca o moldura al efecto y atándose juntas en los extremos (por ejemplo, Tylecote 1987: 184). En el ambiente del Sitio 15 las condiciones de conservación de instrumentos como los mencionados son malas. Sin embargo, como fuera mencionado líneas atrás, en algunos fragmentos recuperados y atribuidos a bordes de crisoles se reconocieron rasgos que probablemente se relacionaron con la aplicación de instrumentos de sujeción de este tipo (González, L. 2004: 97).

No obstante, se constató que otros fragmentos, mucho menores en número, presentan una acanaladura cerca del borde, muy prolija y de sección semicircular ("media caña"), los cuales, por lo menos en dos casos, se recuperaron asociados a fragmentos más pequeños desprendidos de la cara externa adyacente a la boca de los recipientes. Una vez remontados los fragmentos, se comprobó que quedaba en el interior de la pared un canal circular de unos $3 \mathrm{~mm}$ de diámetro, que acompañaba la circunferencia de la pieza (fig. 13). En otros cinco casos en que fue detectada la acanaladura, no se identificaron los fragmentos complementarios. Acerca de la manufactura del canal, es probable que los recipientes se modelaran colocando un cordón de

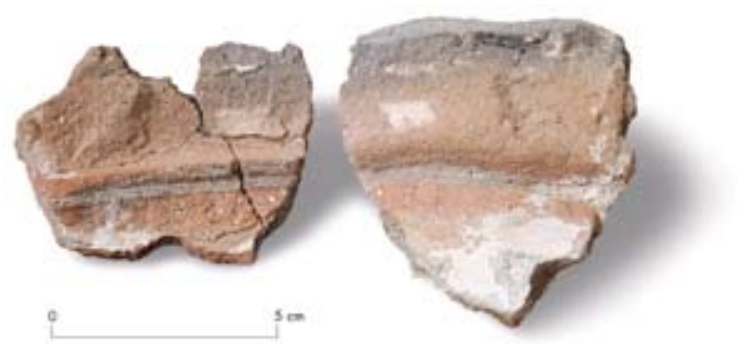

Figura 13. RCh 15, fragmentos de un crisol con canal interno perimetral. La pieza de la izquierda corresponde a la pared externa y ajusta con la restante, formando el canal interior.

Figure 13. RCh 15, fragment of a crucible with an internal channel around the perimeter. The piece on the left corresponds to an external wall and fits together with the internal to form the interior channel.

fibra vegetal o animal (en dos ejemplares se observan improntas que se corresponden con un cordón) o aun de cera, con la pasta fresca, el que luego se tapaba con arcilla. Al cocerse la pieza, el cordón se quemaría, dejando liberado el canal. El curioso rasgo tecnológico de estos crisoles, denominado CIP (canal interno perimetral), fue interpretado con relación al transporte de los recipientes hacia los moldes donde se volcaría el 
metal fundido (González \& Gluzman 2009; Gluzman et al. 2009), aunque se está lejos de comprender en su totalidad el modo de operación. Es probable que por el canal pasara un elemento que tendría salida al exterior en un par de lugares de la circunferencia del recipiente, de tal forma que pudieran acoplarse mangos con los cuales los artesanos levantarían la pieza. Por supuesto, el elemento que recorrería el canal debería ser el adecuado para resistir las tensiones derivadas de las altas temperaturas.

Sobre el particular, es útil consignar que entre los restos de refractarios recuperados en la localidad de Barrealito, provincia de San Juan, por Salvador Debenedetti (1917) y depositados en el Museo Etnográfico de Buenos Aires, se identificaron dos piezas que exhibían CIP. Entre los materiales procedentes del mismo contexto se encontraban tres fragmentos de alambre de bronce (Sn 4.97\%) y sección rectangular que se adecuaban perfectamente a los canales (fig. 14). No obstante, al momento resulta arriesgado afirmar que estos alambres fueran los elementos de sostén de los recipientes, toda vez que se desconoce la dinámica física de la interacción de los materiales a altas temperaturas.

\section{METALES Y METALURGISTAS EN RINCON CHICO}

Los datos generados a partir de las investigaciones en el taller del Sitio 15 permitieron formular una serie de propuestas sobre la organización de la producción de metales, el estilo tecnológico aplicado y el papel que los bienes elaborados y los elaboradores jugaron en el marco de la sociedad mayor. Todo apunta a indicar que la ocupación del Sitio 15 se inició a fines del siglo Ix, con las prácticas metalúrgicas concentradas en la parte

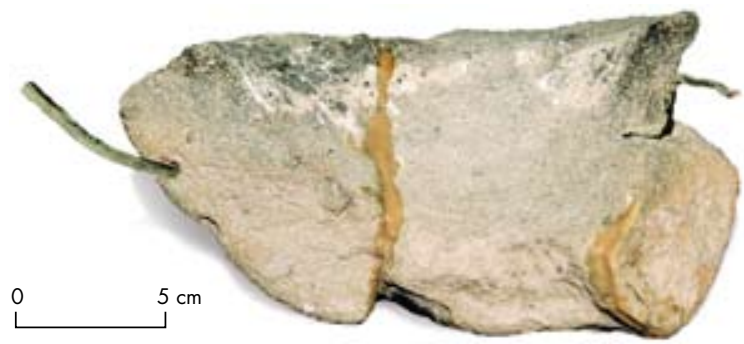

Figura 14. Fragmento de crisol de Barrealito (Debenedetti 1917 , Museo Etnográfico) con canal interno perimetral. El alambre, si bien pertenece al mismo contexto, fue colocado sólo para ilustrar el rasgo.

Figure 14. Fragment of a crucible from Barrealito (Debenedetti 1917, Museo Etnográfico) with an interior channel around the perimeter. The wire belongs to the same context but was placed only to illustrate the feature. central de MO, lugar que ostenta uno de los fechados más antiguo del taller (960 \pm 70 años $\mathrm{C}^{14}$ AP, LP-248).

Paulatinamente se fueron incorporando nuevas áreas de trabajo, hacia el norte y el sur, con remodelaciones arquitectónicas. La reducción de minerales y la fusión de metales se realizaban en crisoles calentados en fogones, aplicándose ventilación forzada mediante sopladores de boca con el propósito de alcanzar los rangos térmicos requeridos. Al parecer, en torno al siglo XIII la organización sociopolítica de Rincón Chico habría experimentado un marcado incremento en su complejidad, lo cual promovió la producción de bienes de prestigio y relacionados con las prácticas ceremoniales, situación que, a su vez, favoreció el crecimiento en la escala de las actividades metalúrgicas. La máxima intensidad de las actividades se habría alcanzado a fines del siglo xIv, cuando operaban en forma relativamente simultánea varias áreas de trabajo dedicadas a tareas específicas y complementarias dentro de la secuencia de producción metalúrgica (Tarragó \& González 1996; González, L. 2001 Ms.).

La integración de la región al estado inkaico, durante la primera mitad del siglo xv, encontraría al taller en plena actividad, con artesanos experimentados y conocedores de los secretos del oficio y que, además, producían desde tiempo antes bronce estañífero, aleación considerada como la marca de fábrica de la metalurgia inkaica (Lechtman 1978: 511, 2007: 328; Earle 1997: 189). La ocupación cusqueña se tradujo en un mayor nivel de procesamiento tecnológico, habilitándose en MM una batería de hornos que habrían operado según el principio de uno de los tipos de huayra andina descritos por varios cronistas (véase van Buren 2005: 134). Es probable que también se modificara el sistema de aprovisionamiento de materias primas y que, en el ámbito del taller, los antiguos espacios de trabajo y otros nuevos que se abrieron en el sector norte pasaran a cumplir diferentes funciones. No obstante, las evidencias muestran que se continuó con la reducción de minerales, refundición de prills y preparación de aleaciones mediante el método tradicional de crisoles calentados en fogones y ventilados con sopladores, manteniéndose el MO como área de trabajo preferencial (González, L. 2001 Ms.; González \& Gluzman 2007a).

Otra innovación atribuible a la administración inkaica fue la elaboración de lingotes, comportamiento probablemente relacionado con la movilización de metales base hacia otros lugares. No obstante, no se registran evidencias que permitan sostener que se haya intentado estandarizar las aleaciones cobre-estaño, como fuera postulado para otras situaciones andinas (por ejemplo, Earle 1994: 456; véase González \& Gluzman 2007b). 
De igual modo, si bien es probable que en el taller comenzaran a elaborarse objetos metálicos del catálogo estatal, los bienes reconocidos localmente siguieron fabricándose. Tampoco las cualidades de los refractarios sufrieron variaciones.

Por otro lado, las evidencias indican que el taller, más allá de las actividades tecnológicas, no estaba divorciado de la vida doméstica y que, además, como se indicara, estaba asociado con áreas funerarias, estableciendo un vínculo espacial y simbólico entre el ámbito habitacional y de trabajo y el lugar de los ancestros (Tarragó 2007). Al respecto, se ha planteado que la unidad social que construyó y ocupó los primeros recintos fue la que detentaba el conocimiento técnico para la elaboración del bronce y que, con el transcurso del tiempo y el incremento de las actividades productivas, fue sumándose mano de obra temporaria desde unidades residenciales vecinas (Tarragó 2007: 24-25). El hecho que los objetos elaborados en el taller, en su mayor parte no utilitarios, no fueron consumidos en la unidad productiva, sugiere que los bienes atendían a una demanda externa, habiéndose propuesto que los metalurgistas fueron constituyéndose como operarios especializados que, con el dominio de tecnología y conocimientos específicos, al menos durante una parte del año se encargaban de proveer de bienes de distinción a los grupos sociales dominantes (Tarragó \& González 1996: 89).

\section{MAESTROS DEL FUEGO}

A lo largo de su prolongada historia, la estirpe metalúrgica del taller del Sitio 15 fue desarrollando un estilo tecnológico propio que se manifestó no sólo en las cualidades de los objetos terminados, sino también en los procedimientos instrumentados para realizarlos. Pero, así como la materialidad de un objeto de metal implica una multitud de dimensiones analíticamente indivisibles (Martinón-Torres \& Rehren 2009), las técnicas de manufactura no pueden ser comprendidas si son vistas solamente como acciones mecánicas aplicadas a la materia. Por el contrario, toda tradición técnica surge con relación a un contexto sociohistórico determinado (Pffaffenberger 1992: 282-283; Mackay \& Gillespie 1992: 688; Tarragó \& González 1996: 88). Así, del mismo modo que los objetos elaborados materializaban ciertos elementos del sistema de representaciones dominante (véase, entre varios, González, A. 1992; González, L. 2008), los procesos de producción puestos en marcha para realizarlos estaban cargados de ideología. Los artefactos y las estructuras de trabajo y su modo de operación funcionaron como símbolos que otorgaron a los artesanos del metal atributos culturales específicos, afirmando y haciendo visibles un conjunto particular de juicios en el fluido proceso de clasificación social de personas y eventos (Beaudry et al. 1991: 154). De tal forma, al tiempo que los metalurgistas creaban objetos significativos también forjaban su propia identidad social (Janusek 1999: 110) y más que receptores pasivos de la demanda de los grupos sociales dominantes, eran actores activos en la producción y reproducción de los valores y símbolos culturales, compartiendo intereses similares a los de aquellos (Pffaffenberger 1992: 282-283; Williams \& Edge 1996: 873; Klein \& Kleinman 2002: 40; Olsen \& Engen 2007: 458).

La disposición de las estructuras del taller y de sus áreas del trabajo admiten lecturas que pueden enriquecer la comprensión de la organización social de las actividades desarrolladas. Como fuera señalado, el conjunto arquitectónico del sitio, observado desde el resto del asentamiento, ofrece una comunicación visual y física negativa, toda vez que el acceso a la estructura principal, E1, se planificó en su costado oriental. El área de actividades metalúrgicas utilizada con reiteración durante toda la trayectoria histórica del taller, el MO, se ubica aún más al oriente, conformando de tal forma un espacio sólo accesible para los operarios del taller. La construcción de un ámbito de trabajo metalúrgico oculto y periférico es una característica repetidamente observada en sociedades etnográficas preindustriales y que obedece tanto a consideraciones prácticas, por ejemplo la disponibilidad de combustibles y de vientos, como a factores que, a primera vista, nada tienen que ver con lo técnico pero que son evaluados por los artesanos como clave para el éxito de las operaciones. Por ejemplo, evitar la contaminación con las fuerzas negativas del común de la gente y desarrollar en forma adecuada el ceremonialismo de la transformación, mediante el fuego, del mineral en metal (entre otros, Sapir 1981; Childs 1991; Herbert 1993; Goucher \& Herbert 1996; De Barros 2000; Haaland et al. 2006). En el caso del Sitio 15, el MO se ubicaba en un espacio adyacente al antiguo bosque de maderas duras, y favorablemente expuesto a los vientos. Pero queda lugar para pensar también en una estrategia deliberada de ocultamiento de las operaciones y, tal vez, rodearlas de un aura mística con la intervención de potencias sobrenaturales que sólo los metalurgistas podían manejar. Esta estrategia les reaseguraría, por una parte, el monopolio del saber técnico y esotérico, fortaleciendo su posición a la hora de la disputa por el poder social. Pero, por otro lado, la autoexclusión pudo constituir un sólido mecanismo de reafirmación de la identidad del grupo participante (Njoku 1991: 213; Finneran 2003: 43; Pryce et al. 2007: 
554). Desde esta mirada, el MO aparece como un espacio ritual en el cual cada evento de fundición era, al tiempo que una operación técnica, una instancia de renovación de los lazos con los ancestros fundadores del linaje metalurgista.

Otro aspecto técnico que merece subrayarse es que en el taller, durante siglos, para fundir minerales y preparar aleaciones se utilizaron crisoles calentados en fogones ventilados con sopladores de boca. Esta modalidad se mantuvo durante la ocupación inkaica, cuando en el sector MM fue instalada una batería de huayra, a pesar de que, como fuera adelantado, es probable que a partir de ese momento el antiguo procedimiento haya sido integrado a una organización productiva diferente. La persistencia de esta modalidad pirometalúrgica durante al menos 600 años impresiona como significativa si se trasciende su grado de eficiencia técnica para incorporar probables pulsiones superestructurales que dictaminaban sobre la forma correcta en que los metalurgistas debían relacionarse con la transformación de las materias primas y las cualidades esenciales que debían contener los productos obtenidos. Al respecto, la situación muestra similitudes con lo planteado para la costa norte de Perú, donde a partir del siglo x la sociedad Sicán había desarrollado una suprema maestría en la preparación de bronce arsenical, utilizando hornillos cuyas temperaturas eran incrementadas mediante la fuerza pulmonar de los operarios (Shimada 1994). Experimentos realizados en Cerro Huaringa mostraron que equipos de 2 a 5 hombres, soplando de 10 a 30 minutos cada uno, al cabo de tres horas obtenían productos similares a los de los antiguos metalurgistas (Shimada \& Merkel 1991). Pero también se tomó nota de las dificultades para mantener rangos térmicos adecuados. De hecho, el uso de sopladores no permitía alcanzar temperaturas suficientes para lograr lingotes, sino gotas de metal que eran luego recuperadas y refundidas. No obstante estas limitaciones, durante 600 años la modalidad se mantuvo en operación, incluso bajo las dominaciones Chimú e Inka (Shimada 1994: 59). En su elegante análisis del caso, Epstein (1996) señaló que en los comportamientos técnicos se aplican elecciones que deben conjugarse con un sistema de creencias más amplio, subrayando la importancia en el pensamiento andino de la respiración y el aliento como fuerza vital que los artesanos podían transmitir a los objetos que elaboraban (Epstein 1996: 131; véase Sillar 2000: 58, Hastorf 2003: 310).

Algunos de los refractarios desarrollados por los metalurgistas del taller del Sitio 15 parecen haber tenido modos de operación cuya complejidad requiere de mayores estudios. Sin embargo, los casos de las cucharas y del método de sujeción que denominamos CIP asoman, al momento, como ejemplos de elecciones tecnológicas en las cuales la racionalidad dependió tanto de criterios funcionales como de los factores sociales e ideológicos que rodearon a esas elecciones (Pffaffenberger 1992: 283). Sobre el particular, se propuso que estos y otras sugestivas innovaciones (por ejemplo, el uso de cenizas de huesos para el recubrimiento de los refractarios) podrían encuadrarse en comportamientos deliberados de los artesanos para aumentar los "secretos" de las actividades y exagerar el gasto de energía de trabajo, con lo cual crecía el potencial de información de los objetos producidos y se reafirmaba su consumo conspicuo (Clark \& Parry 1990: 296; Inomata 2001: 333). Al mismo tiempo, el gasto de energía iba acompañado por la aplicación de una formidable dosis de conocimiento técnico, todo lo cual redundaría en el prestigio de los artesanos y apuntalaría su situación en la competencia por los lugares de poder social (González \& Gluzman 2009; Gluzman et al. 2009).

\section{PALABRAS FINALES}

La metalurgia del Noroeste prehispánico, basada en el bronce, asumió una identidad particular dentro del concierto andino. Esta identidad quedó expresada no sólo en las cualidades formales y expresivas de los bienes elaborados, sino también en las opciones técnicas desarrolladas por los antiguos metalurgistas. En particular durante las épocas tardías, con el aumento de la escala de producción promovido por la dinámica sociohistórica, la creatividad e idoneidad de los artesanos para trabajar el bronce se exhibieron en su total dimensión en los objetos ornamentales. Todo apunta a indicar, además, que la elaboración de estos objetos, con el control de una compleja y costosa cadena de trabajo, en algunas zonas del Noroeste constituyó un objetivo estratégico dentro del proceso de diferenciación social y de institucionalización de las actividades ceremoniales.

El aumento paulatino de la complejidad social y la creciente demanda de bienes de metal se reflejó en la formalización de espacios productivos específicos, siendo, tal vez, el caso del Sitio 15 de Rincón Chico el ejemplo más ilustrativo. Las investigaciones realizadas permiten contar con un panorama bastante ajustado de la trayectoria histórica del taller, caracterizada por un continuo crecimiento, remodelaciones del espacio y habilitación de nuevas áreas de producción. Durante esta trayectoria, al tiempo que se incorporaban algunas innovaciones en el utillaje de trabajo, los operarios se encargaron de preservar, aun bajo la administración 
inkaica, ciertos elementos de su particular tradición para encarar las operaciones tecnológicas. Esta tradición conformó un entramado en el cual las elecciones técnicas estuvieron matizadas con vigorosos detalles simbólicos y que consolidó a la estirpe de metalurgistas.

Aunque algunos de estos elementos deben ser todavía estudiados con mayor profundidad para comprender su desarrollo y efectiva operación, en su conjunto dan pie para sugerir que los metalurgistas del Sitio 15 -propietarios del conocimiento ancestral, técnico y esotérico que permitía llevar adelante las dramáticas transformaciones de la materia- se emparentaron con el prestigio y la sacralidad de los bienes que elaboraban y, a través de ellos y de sus procedimientos de producción, fueron protagonistas principales en la dinámica de la sociedad en la que participaron.

RECONOCIMIENTOS Las investigaciones en el Sitio 15 se realizaron en el marco de diversos proyectos financiados por la Universidad de Buenos Aires, CONICET y ANPCYT y dirigidos por la Dra. Myriam N. Tarragó, a quien agradezco su permanente apoyo, guía y generosidad. También agradezco a Heather Lechtman su aliento, consejos y comentarios. Mi reconocimiento para muchos colegas que colaboraron inestimablemente en los trabajos de campo y de laboratorio, en particular Geraldine Gluzman, Juan Manuel Estévez, Héctor Buono, Carlos Belotti y Marcelo Lamami. Las atinadas observaciones de Catriel Greco y de Romina Spano fueron importantes para mejorar varios aspectos del trabajo. De todas formas, lo vertido en estas páginas es de mi única responsabilidad.

\section{REFERENCIAS}

Angiorama, C., 2005. Nuevas evidencias de actividades metalúrgicas pre-incaicas en la Quebrada de Humahuaca (Jujuy, Argentina). Anales del Museo de América 13: 173-198.

BeAudry, M.; L. CoOK \& S. Mrozowski, 1991. Artifacts and active voices: material culture as social discourse. En The Archaeology of Inequality, R. McGuire \& R. Paynter, Eds., pp. 201-218. Oxford: Blackwell.

Childs, S. T., 1991. Style, technology and iron smelting furnaces in Bantu speaking Africa. Journal of Anthropological Archaeology 10: $332-359$

Clark, J. E. \& W. J. Parry, 1990. Craft Specialization and Cultural Complexity. Research in Economic Anthropology 12: 289346.

De Barros, P., 2000. Iron metallurgy: sociocultural context. En Ancient African metallurgy. The sociocultural context, M. Vison, S. Childs, P. de Barros \& A. Holl, Eds., pp. 147-198. Walnut Creek: Altamira Press.

DeBENEDetTI, S., 1917. Investigaciones arqueológicas en los valles preandinos de la provincia de San Juan. Publicaciones Sección Antropología 15. Facultad de Filosofía y Letras, Universidad de Buenos Aires.

De Oliveira, F.; D. Lajo, L. Senta, L. De Miranda \& E. D'Elía, 2009 Study of patina formation on bronze specimens. Materials Chemistry and Physics 115: 761-770.

Earle, T., 1994. Wealth finance in the Inka empire: evidence from the Calchaqui valley, Argentina. American Antiquity 59 (3) 443-460.

1997. How chiefs come to power. The political economy in prebistory. Stanford: Stanford University Press.
Epstein, S., 1996. Le cuivre, le fer et le soufflé humain. Culture et technique dans la fonte andine prehispanique. Techniques $\mathcal{E}$ Culture 27: 125-136.

FinNeran, N., 2003. Ethiopian evil eye belief and the magical symbolism of iron working. Folklore 114 (3): 427-433.

Gluzman, G.; L. González, M. Martinón-Torres \& C. Odriozola LLORET, 2009. Technical ceramics and metallurgical secrets: the case of prehispanic Rincón Chico workshop (NW Argentina). En Proceedings 10th European Meeting on Ancient Ceramics, London (en prensa).

GonZález, A., 1992. Las placas metálicas de los Andes del Sur. Materialen zur Allgemeinen und Vergleichenden Archaologica Band 46. Mainz am Rhein: Verlag Philipp von Zabern.

— 1998. Cultura La Aguada. Arqueología y diseños. Buenos Aires: Filmediciones Valero.

GoNZÁlez, L., 1992. Fundir es morir un poco. Restos de actividades metalúrgicas en el valle de Santa María, provincia de Catamarca. Palimpsesto. Revista de Arqueología 2: 51-70.

— 1997. Cuerpos ardientes. Interacción surandina y tecnología metalúrgica. Estudios Atacameños 14: 189-210.

— 2001 Ms. Tecnología y dinámica social. La producción metalúrgica prehispánica en el Noroeste Argentino. Tesis Doctoral, Facultad de Filosofía y Letras, Universidad de Buenos Aires.

— 2002a. A sangre y fuego. Nuevos datos sobre la metalurgia Aguada. Estudios Atacameños 24: 21-37.

- 2002b. Heredarás el bronce. Incas y metalurgia en el Noroeste Argentino. Intersecciones en Antropología 3: 55-68.

— 2004. Bronces sin nombre. La metalurgia prebispánica en el Noroeste Argentino. Buenos Aires: Ediciones Fundación CEPPA.

— 2008. La rebelión de los bronces. Estudios sobre metalurgia prehispánica en el Noroeste Argentino. En Mina y metalurgia en los Andes del Sur desde la época prehispánica al siglo XVII, P. Cruz \& J. Joinville-Vacher Eds., pp. 57-89. Sucre: IRD-IFEA.

Gonź́lez, L. \& G. Gluzman, 2007a. Nuevas evidencias del taller metalúrgico prehispánico de Rincón Chico 15 (provincia de Catamarca). En Actas del Primer Congreso Argentino de Arqueometría, pp. 41-50, Rosario.

-2007b. Innovación y continuidad en la metalurgia del Noroeste argentino. Mundo de Antes 5: 187-210.

— 2009. Agárrame si puedes. Métodos de sujeción de crisoles en el taller metalúrgico prehispánico de Rincón Chico 15. Anuario Arqueológico 1: 139-152.

González, L.; G. Gluzman, H. Buono, J. Estévez \& E. Cabanillas, 2007. Arqueometalurgia experimental aplicada al taller de Rincón Chico 15, valle de Yocavil. En Actas del XVI Congreso Nacional de Arqueología Argentina, Tomo I, pp. 587-592, Jujuy.

GonzÁlez, L.; G. Gluzman \& J. Estévez, 2008. Los metales prehispánicos del Noroeste argentino. Contextos de producción y trayectoria histórica. En Actas del VI Congreso Argentino de Americanistas, Tomo 2, pp. 199-219, Buenos Aires.

Goucher, C. \& E. Herbert, 1996. The blooms of Banjeli: technology and gender in West Africa iron making. En The Culture and Technology of African Iron Production, P. Schmidt, Ed., pp. 40-57. Gainesville: University Press of Florida.

Graffam, G.; M. Rivera \& A. Carevic, 1994. Copper smelting in the Atacama: ancient metallurgy at the Ramaditas site, Northern Chile. En In Quest of Mineral Wealth. Aboriginal and Colonial Mining and Metallurgy in Spanish America, A. Craig \& R. West, Eds., pp. 75-92. Baton Rouge: Louisiana State University.

HaAland, G.; R. HaAland \& D. Dea, 2006. Furnace and pot: why the iron smelter is a big pot maker. Azania 39: 146-165.

Hastorf, C., 2003. Community with the ancestors: ceremonies and social memory in the Middle Formative at Chiripa, Bolivia. Journal of Anthropological Archaeology 22: 305-332.

HERBERT, E., 1993. Iron, gender, and power. Rituals of transformation in African societies. Bloomington: Indiana University Press.

InOMATA, T., 2001. The power and ideology of artistic creation. Elite craft specialists in Classic Maya society. Current Anthropology 42 (3): 321-349. 
JANUSEK, J. W., 1999. Craft and local power: embedded specialization in Tiwanaku cities. Latin American Antiquity 10 (2): 107-131.

Klein, H. \& D. Kleinman, 2002. The social construction of technology: structural considerations. Science, Technology \& Human Values 27 (1): 28-52.

Lechtman, H., 1978. Temas de metalurgia andina. En Tecnología Andina, R. Ravines, Comp., pp. 489-520. Lima: IEP.

— 1999. Afterword. En The Social Dynamics of Technology. Practice, Politics and World of Views, M. Dobres \& C. Hoffman, Eds., pp. 223-232. Washington: Smithsonian Institution Press.

-2007. The Inka and Andean metallurgical tradition. En Variations in the Expresion of Inka Power, R. Burger, C. Morris \& R. Ramos Mendieta, Eds., pp. 313-356. Washington: Dumbarton Oaks.

MaCKAY, H. \& G. Gillespie, 1992. Extending the social shaping of technology approach. Social Studies of Science 22 (4): 685-716.

Martinón-Torres, M. \& T. Rehren, 2009. Post-Medieval crucibles production and distribution: a study of materials and materialities. Archaeometry 51 (1): 49-74.

Niemeyer, H., 1981. Dos tipos de crisoles prehispánicos del Norte Chico, Chile. Boletín del Museo Arqueológico de La Serena 17: 92-109.

NJoku, O., 1991. Magic, religion and iron technology in precolonial North Western Igboland. Journal of Religion in Africa 21 (3): 194-215.

Olsen, O. \& O, Engen, 2007. Technological change as a trade-of between social construction and technological paradigms. Technology in Society 29: 456-468.

Pffaffenberger, B., 1992. Technological dramas. Science, Technology E Human Values 17 (3): 282-312.

Pradell, T.; L. González \& G. Gluzman, 2009. Estudios técnicos de materiales refractarios del Noroeste Argentino. En Actas del Tercer Congreso Argentino de Arqueometría, Córdoba (en prensa).

Pryce, T.; Y. Bassiakos, M. Catapotis \& R. Doonan, 2007. "Decaerimoniae" Technological choices in copper smelting furnace design at early bronze age Chrysokamino, Crete. Archaeometry 49 (3): 543-557.

Raffino, R.; R. Iturriza, A. Iácona, A. Capparelli, D. Gobbo, V. Montes \& R. VÁzQuez, 1996. Quillay: centro metalúrgico Inka en el Noroeste Argentino. Tawantinsuyu 2: 59-69.

ROVIRA, S., 2004. Tecnología metalúrgica y cambio cultural en la prehistoria de la península ibérica. Norba. Revista de Historia 17: 9-40.
SAPIR, J. D., 1981. Leper, hyena, and blacksmith in Kujamaat Diola thought. American Ethnologist 8 (3): 526-543.

ScotT, D., 2000. A review of copper chlorides and related salts in bronze corrosion and as painting pigments. Studies in Conservation 45 (1): 39-53.

Shimada, I., 1994. Pre-hispanic metallurgy and mining in the Andes: recent advances and future tasks. En In Quest of Mineral Wealth: Aboriginal and Colonial Mining in Spanish America, A. Craig \& R. West, Eds., pp. 37-73. Baton Rouge: Lousiana State University.

Shimada, I. \& J. Merkel, 1991. Copper alloy metallurgy in ancient Peru. Scientific American 265 (1): 80-86.

SiLLAR, B., 2000. Dung by preference: the choice of fuel as an example of how Andean pottery production is embedded within wider technical, social and economic practices. Archaeometry 42 (1): 43-60.

TARragó, M., 1998. El patrimonio del valle de Santa María en peligro. En 50 años de aportes al desarrollo y consolidación de la antropología argentina. Homenaje a Alberto Rex González, pp. 205-253. Buenos Aires: Facultad de Filosofía y Letras / Fundación Argentina de Antropología.

— 2007. Ámbitos domésticos y de producción artesanal en el Noroeste Argentino prehispánico. Intersecciones en Antropología 8: $15-26$.

Tarragó, M. \& L. González, 1996. Producción especializada y diferenciación social en el sur del valle de Yocavil. Anales de Arqueología y Etnología 50/51: 85-108.

-2004. Arquitectura social y ceremonial en Yocavil, Catamarca. Relaciones de la Sociedad Argentina de Antropología 29: 297-316.

Tylecote, R., 1974. Can copper be smelted in a crucible? Journal of the Historical Metallurgy Society 8 (11): 54.

- 1987. The early history of metallurgy in Europe. London: Longman.

UCEDA, S. \& C. RENGifo, 2006. La especialización del trabajo: teoría y arqueología. El caso de los orfebres Mochica. Bulletin IFEA 35 (2): 149-185.

VAN BuREN, M., 2005. Un estudio etnoarqueológico de la tecnología de fundición en el sur de Potosí, Bolivia. Textos Antropológicos 14 (2): 133-148.

Williams, R. \& D. EDGe, 1996. The social shaping of technology. Research Policy 25: 865-899. 